\title{
Liquid Air Energy Storage for Decentralized Micro Energy Networks with Combined Cooling, Heating, Hot Water and Power Supply
}

\section{SHE Xiaohui ${ }^{1}$, ZHANG Tongtong ${ }^{1}$, PENG Xiaodong ${ }^{1}$, WANG Li ${ }^{2}$, TONG Lige $^{2}$, LUO Yimo ${ }^{3}$, ZHANG Xiaosong ${ }^{4}$, DING Yulong, ${ }^{1, *}$}

1. Birmingham Centre for Energy Storage \& School of Chemical Engineering, University of Birmingham, Birmingham B15 2TT, UK

2. School of Energy and Environmental Engineering, University of Science \& Technology Beijing, Beijing 100083, China

3. College of Civil Engineering, Hunan University, Changsha 410082, China

4. School of Energy and Environment, Southeast University, Nanjing 210096, China

(C) The Author(s) 2020

\begin{abstract}
Liquid air energy storage (LAES) has been regarded as a large-scale electrical storage technology. In this paper, we first investigate the performance of the current LAES (termed as a baseline LAES) over a far wider range of charging pressure (1 to $21 \mathrm{MPa}$ ). Our analyses show that the baseline LAES could achieve an electrical round trip efficiency (eRTE) above $60 \%$ at a high charging pressure of $19 \mathrm{MPa}$. The baseline LAES, however, produces a large amount of excess heat particularly at low charging pressures with the maximum occurred at $\sim 1$ MPa. Hence, the performance of the baseline LAES, especially at low charging pressures, is underestimated by only considering electrical energy in all the previous research. The performance of the baseline LAES with excess heat is then evaluated which gives a high eRTE even at lower charging pressures; the local maximum of $62 \%$ is achieved at $\sim 4 \mathrm{MPa}$. As a result of the above, a hybrid LAES system is proposed to provide cooling, heating, hot water and power. To evaluate the performance of the hybrid LAES system, three performance indicators are considered: nominal-electrical round trip efficiency (neRTE), primary energy savings and avoided carbon dioxide emissions. Our results show that the hybrid LAES can achieve a high neRTE between $52 \%$ and $76 \%$, with the maximum at $\sim 5 \mathrm{MPa}$. For a given size of hybrid LAES $(1 \mathrm{MW} \times 8 \mathrm{~h})$, the primary energy savings and avoided carbon dioxide emissions are up to 12.1 MWh and 2.3 ton, respectively. These new findings suggest, for the first time, that small-scale LAES systems could be best operated at lower charging pressures and the technologies have a great potential for applications in local decentralized micro energy networks.
\end{abstract}

Keywords: liquid air energy storage, cryogenic energy storage, micro energy grids, combined heating, cooling and power supply, heat pump

\section{Introduction}

Liquid air energy storage (LAES) is gaining increasing attention for large-scale electrical storage in recent years due to the advantages of high energy density, ambient pressure storage, no geographical constraints and potentially highly competitive costs. These features make the LAES technology attractive for load-shifting of 


\begin{tabular}{|c|c|c|c|}
\hline \multicolumn{4}{|c|}{ Nomenclatures } \\
\hline $\mathrm{COP}_{\mathrm{c}}$ & Cooling performance of the mechanical chiller & $\mathrm{PH}$ & Power and Hot water \\
\hline $\mathrm{COP}_{\mathrm{h}}$ & $\begin{array}{l}\text { Heating performance of the air source heat } \\
\text { pump }\end{array}$ & PHC & Power, Hot water and Cooling \\
\hline$e$ & Specific exergy $/ \mathrm{kJ}^{\mathrm{k}} \mathrm{kg}^{-1}$ & PHH & Power, Hot water and Heating \\
\hline$h$ & Specific enthalpy $/ \mathrm{kJ} \cdot \mathrm{kg}^{-1}$ & Subscripts & \\
\hline$m$ & Mass flow rate $/ \mathrm{kg} \cdot \mathrm{s}^{-1}$ & abs & Absorber \\
\hline$P$ & Pressure/MPa & $\mathrm{amb}$ & Ambient \\
\hline$Q$ & Heat load $/ \mathrm{kW}$ & $\mathrm{ch}$ & Charging process \\
\hline$r$ & Pressure ratio & com & Compressor \\
\hline$s$ & Specific entropy $/ \mathrm{kJ} \cdot \mathrm{kg}^{-1} \cdot \mathrm{K}^{-1}$ & cool & Cooling capacity \\
\hline$T$ & Temperature/K & cry-tur & Cryo-turbine \\
\hline$t$ & Time/h & dis & Discharging process \\
\hline$W$ & Power consumption/generation/kW & E_RTE & Electrical Round Trip Efficiency \\
\hline Y & Liquid air yield & ex & Excess \\
\hline \multicolumn{2}{|c|}{ Abbreviations } & HPG & High-pressure generator \\
\hline eRTE & Electrical Round Trip Efficiency & h-water & Hot water \\
\hline $\mathrm{HE}$ & Heat Exchanger & LPG & Low-pressure generator \\
\hline HHE & High-temperature Heat Exchanger & $\max$ & Maximum \\
\hline HPG & High-Pressure Generator & NE_RTE & $\begin{array}{l}\text { Nominal-electrical Round Trip } \\
\text { Efficiency }\end{array}$ \\
\hline LAES & Liquid Air Energy Storage & ref & Refrigerant \\
\hline LHE & Low-temperature Heat Exchanger & $\mathrm{s}$ & Isentropic process \\
\hline LPG & Low-Pressure Generator & tur & Air turbines \\
\hline neRTE & Nominal-Electrical Round Trip Efficiency & $\mathrm{w}$ & Water \\
\hline
\end{tabular}

electrical grids and dealing with the intermittency and fluctuation of renewable generation, which has been enjoying significant growth in recent years [1]. For a standalone LAES system (i.e. baseline LAES), the highest round trip efficiency in terms of electrical energy (eRTE) is achieved at $\sim 60 \%$ with a high charging pressure of $\sim 19 \mathrm{MPa}$. Enhancement of the baseline LAES efficiency remains one of the research and development objectives for further improving the competitiveness of the technology.

Recent years have seen an increased number of studies on the LAES technology especially since 2010 . The basic characteristics of the LAES were first evaluated [2-9] and then its configuration was thermodynamically optimized [10-16] which achieved an eRTE of $\sim 60 \%$ at a moderate charging pressure $(12 \mathrm{MPa})$. To further improve the LAES performance, it was suggested to integrate with external cold/heat sources [17-22] and the eRTE could easily go above $70 \%$. Besides power generation, the LAES was also investigated to produce multi-products such as cooling, heating or pure oxygen to improve energy efficiencies or gain more economic benefits [23-26]. A brief summary of the literature is given in the following.

(1) Thermodynamic and economic analyses of the baseline LAES system:

$\mathrm{Li}$ et al. [2] proposed the use of liquid air as a renewable energy carrier and showed its feasibility and competitiveness compared with the use of hydrogen as an energy carrier. Morgan et al. [3] presented the design and testing results of the world's first LAES pilot plant $(350$ $\mathrm{kW} / 2.5 \mathrm{MWh}$ ). They showed that the recycle of highgrade cold during discharging was crucial for achieving a high eRTE. Guizzi et al. [4] thermo-dynamically analyzed the LAES system and identified if and how an acceptable level of eRTE could be achieved. Sciacovelli et al. [5] examined the use of a packed bed to capture, store and recycle the cold energy of liquid air during the discharging step (power recovery) of the LAES and studied how such dynamic behaviour affected the LAES performance. Peng et al. [7] investigated the LAES performance with a packed bed to capture, store and recycle compression heat during the charging step (air liquefaction) and showed an eRTE between 50\% and $62 \%$. She et al. [8] studied the effect of heat/cold storage and heat transfer on the LAES performance and their results reinforced the importance of cold and heat storage. Lin et al. [9] evaluated the economic viability of the baseline LAES (200 MW) based on price arbitrage in the UK, which showed a payback period of less than 10 
years. All the above literature made efforts to thoroughly understand the characteristics of the baseline LAES system with a high charging pressure.

(2) Optimization of the baseline LAES configurations:

As the baseline LAES system has a limited eRTE, some researchers worked to optimize the system configuration. Li et al. [10] presented an optimization methodology for the design of a large-scale gas liquefaction system including the selection of a system configuration and parametric optimization. Morgan et al. [12] optimized the configuration of a cold turbine for the effective utilization of the cold recycle for achieving a targeted eRTE $>50 \%$. Borri et al. [13] performed a preliminary study on the optimal configuration for a microgrid scale liquefaction cycle. They modelled and compared the Linde, Claude and Kapitza cycles in terms of the specific power consumption and found that a two-stage Kapitza cycle gave an optimal solution. Hamdy et al. [14] reported that the addition of an indirect Rankine cycle increased the specific power output of the discharge process by up to $25 \%$, compared with a direct expansion of liquid air. She et al. [15] found that $20 \%$ to $40 \%$ of compression heat in the baseline LAES was difficult to use in a cost-effective way. They therefore proposed the use of the excess heat to drive an organic Rankine cycle and showed the potential to improve the eRTE by $9 \%$ to $12 \%$. After optimization by the above literature, the baseline LAES system is able to achieve a high eRTE of $\sim 60 \%$ at a medium charging pressure of $\sim 12 \mathrm{MPa}$.

(3) The use of external heat or cold sources for enhancing the baseline LAES performance:

To further improve the eRTE, external high-grade heat or cold sources were introduced into the baseline LAES. The high-grade heat from nuclear power plants [17] and solar energy [18] was proposed to improve the power generation of air expansion, which contributed to an eRTE above 70\%. Lee et al. [19] investigated the use of waste cold energy from the regasification of liquefied natural gas (LNG) for liquid air production. They found that the liquefaction process was very efficient, with an exergy efficiency of $94.2 \%$, and the power recovery process had an exergy efficiency of $61.1 \%$. Kim et al. [21] used the recovered cold energy from LNG regasification for air liquefaction and hot energy from natural gas combustion for power generation and achieved an eRTE of $64.2 \%$. Considering that the current integration of the LAES plant with the LNG terminal has little flexibility, She et al. [22] proposed a cold storage method with pressurized propane which allowed the independent operation of the LAES plant and the LNG terminal and achieved an eRTE of $70.6 \%$. From the above literature, it is promising to improve the eRTE of the baseline LAES by integrating with external cold or heat sources. However, it has quite limited applications since the
LAES plant has to be installed next to the cold or heat sources.

(4) The development of multi-functional LAES:

As the end-users have various demands, such as cooling and heating besides power, researchers tried to investigate different functions of the LAES. Ahmad et al. $[23,24]$ studied the use of liquid nitrogen to provide cooling and power demands for residential buildings and claimed an energy saving up to $28 \%$ compared to conventional air conditioning systems. However, the cooling was achieved by sacrificing the cryogenic energy from liquid nitrogen. Al-Zareer et al. [25] investigated the integration of the LAES with a solid-gas sorption cycle driven by the heat generated during air compression. They found that the overall energy and exergy efficiencies were $72.1 \%$ and $53.7 \%$ for a case where the cooling effect was provided at $0^{\circ} \mathrm{C}$. Wang et al. [26] integrated an air separation unit with the LAES to provide heating, power and pure oxygen, which showed a much better economic performance with a short payback period of $\sim 5.7$ years. The above literature was mainly focused on operation of the LAES with a high charging pressure and the system configuration was quite complicated.

From the above literature, little work has been seen so far on the performance of the baseline LAES over a wide range of charging pressures across both subcritical and supercritical regions. In addition, the view so far on the baseline LAES is that it is mainly for large scale applications and has a low eRTE at a low charging pressure. This work aims to re-examine such views through a systematic analysis on the baseline LAES over a wide charging pressure range of 1 to $21 \mathrm{MPa}$. We shall show that the baseline LAES produces a large amount of excess heat especially at low charging pressures, with the maximum achieved at $1 \mathrm{MPa}$. The excess heat can be valuable if the baseline LAES is used in a decentralized micro-energy network for residential communities and/or industrial/commercial centres. In such cases, the performance of the baseline LAES, especially at low charging pressures, is underestimated by only considering electrical energy in all the previous research. Based on these findings, a hybrid LAES is proposed for the provision of cooling, heating, hot water and power for decentralized micro-energy networks. We show a high performance of such a newly proposed system even at low charging pressures.

\section{The Proposed Hybrid LAES}

\subsection{The baseline LAES}

Fig. 1 shows the conceptual and flow diagrams of the baseline LAES, which includes a charging cycle (air liquefaction) and a discharging cycle (power recovery). During off-peak hours, excess electricity is used to 


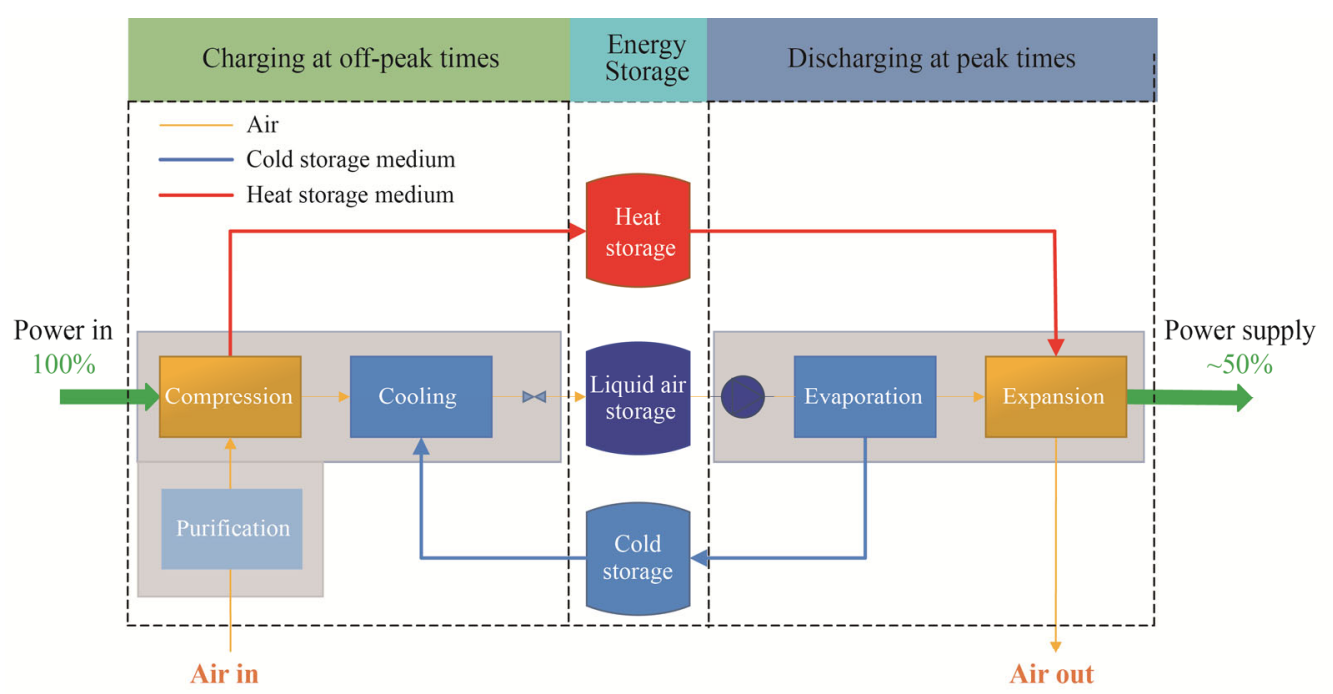

(a) Conceptual diagram

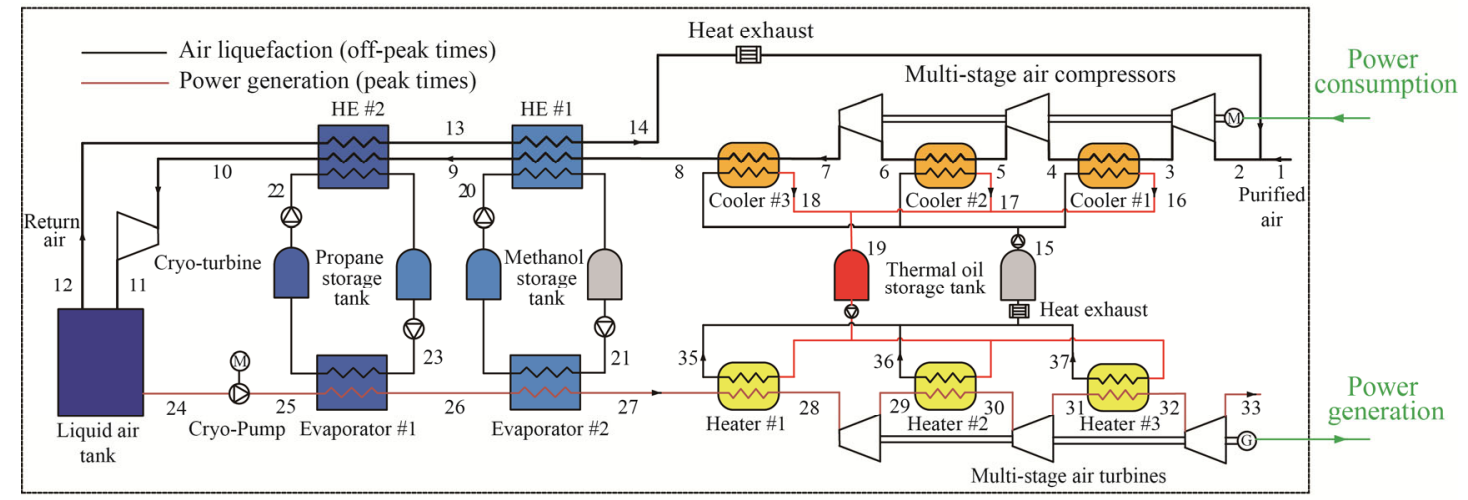

(b) Flow diagram

Fig. 1 The baseline LAES for peak load shifting (i.e. power supply)

liquefy air in the charging cycle: ambient air is first purified to remove water and carbon dioxide (State 1) and then is compressed to the charging pressure (State 8), where heat generated during air compression is captured and stored with thermal oil; the compressed air (State 8) is first cooled by cold methanol (State 20) from a methanol storage tank to bring air to State 9; then, the air is further cooled by cold propane (State 22) from a propane storage tank to bring air to State 10; finally, the low temperature air (State 10) enters a cryo-turbine in which the air expands to State 11 with a part of the air liquefied and stored in a liquid air tank. During peak hours, the stored liquid air is released to produce electricity in the discharging cycle: the liquid air at State 24 is compressed by a cryo-pump to the discharging pressure (State 25); then, it is preheated to an ambient temperature by propane (State 23) and methanol (State 21) in turn, and in the meantime cold energy released by liquid air is stored for air liquefaction in the charging cycle; the high pressure air (State 27) is further heated by the stored hot thermal oil (State 19) to a high temperature; finally, it expands in a multi-stage air turbine for generating electricity.

As mentioned before, the eRTE of a large-scale standalone baseline LAES is $\sim 60 \%$. This implies that the power recovered in the discharging process is only $\sim 60 \%$ of the power consumed in the charging process. An energy balance across the baseline LAES would mean a significant amount of excess heat stored in the thermal oil storage tank (see Section 3.1 for more details).

\subsection{The hybrid LAES}

To make full use of the excess heat, an option is to generate extra electricity through a power generation cycle. However, for cases where LAES plants are close to end users with demands on different forms of energy and/or integrated with local micro-energy networks, the use of the excess heat for power generation is not necessarily the best option. This is because the end users require not only electricity but also cooling, heating and hot water supplies. In addition, the conversion efficiency of low-grade heat $\left(100^{\circ} \mathrm{C}\right.$ to $\left.220^{\circ} \mathrm{C}\right)$ to electricity is very 
low around 20\% [27] and the subsequent use of the electrical energy to produce cooling, heating and/or hot water is not an efficient process and requires more capital investment. We therefore propose a hybrid LAES system that uses the compression heat to generate cooling, heating and hot water (mainly for shower); see Fig. 2 for the conceptual and flow diagrams. This hybrid system is thought to be more flexible, multi-functional, and applicable for small scale applications.

In the hybrid LAES, the cooling is achieved with a double-effect $\mathrm{LiBr}-\mathrm{H}_{2} \mathrm{O}$ refrigeration cycle which gives a cooling temperature of $7^{\circ} \mathrm{C}$; the heating is realized through a heater by heating inlet water at $60^{\circ} \mathrm{C}$ to $85^{\circ} \mathrm{C}$; the domestic hot water at $55^{\circ} \mathrm{C}$, mainly for shower [28], is obtained in a water heater by heating cold tap-water with an average annual temperature of $10^{\circ} \mathrm{C}$ in the UK

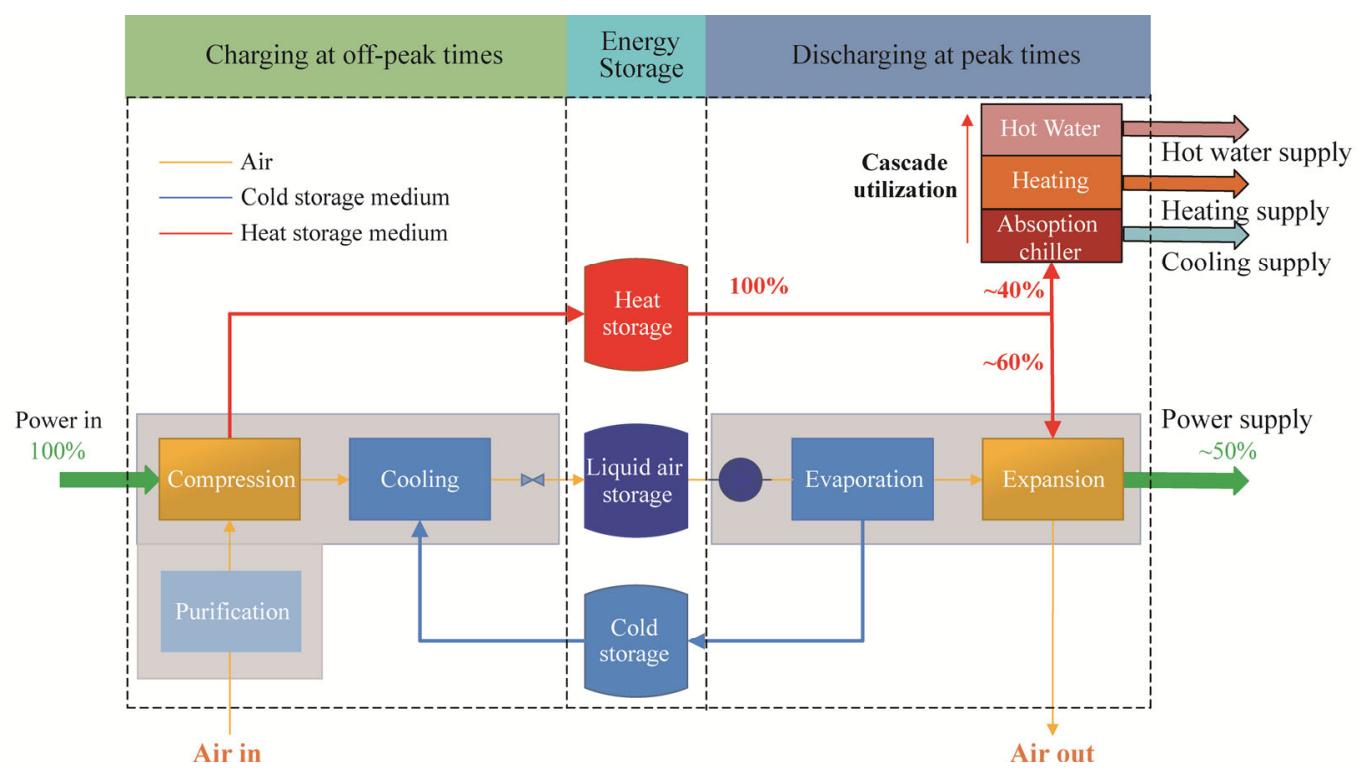

(a) Conceptual diagram

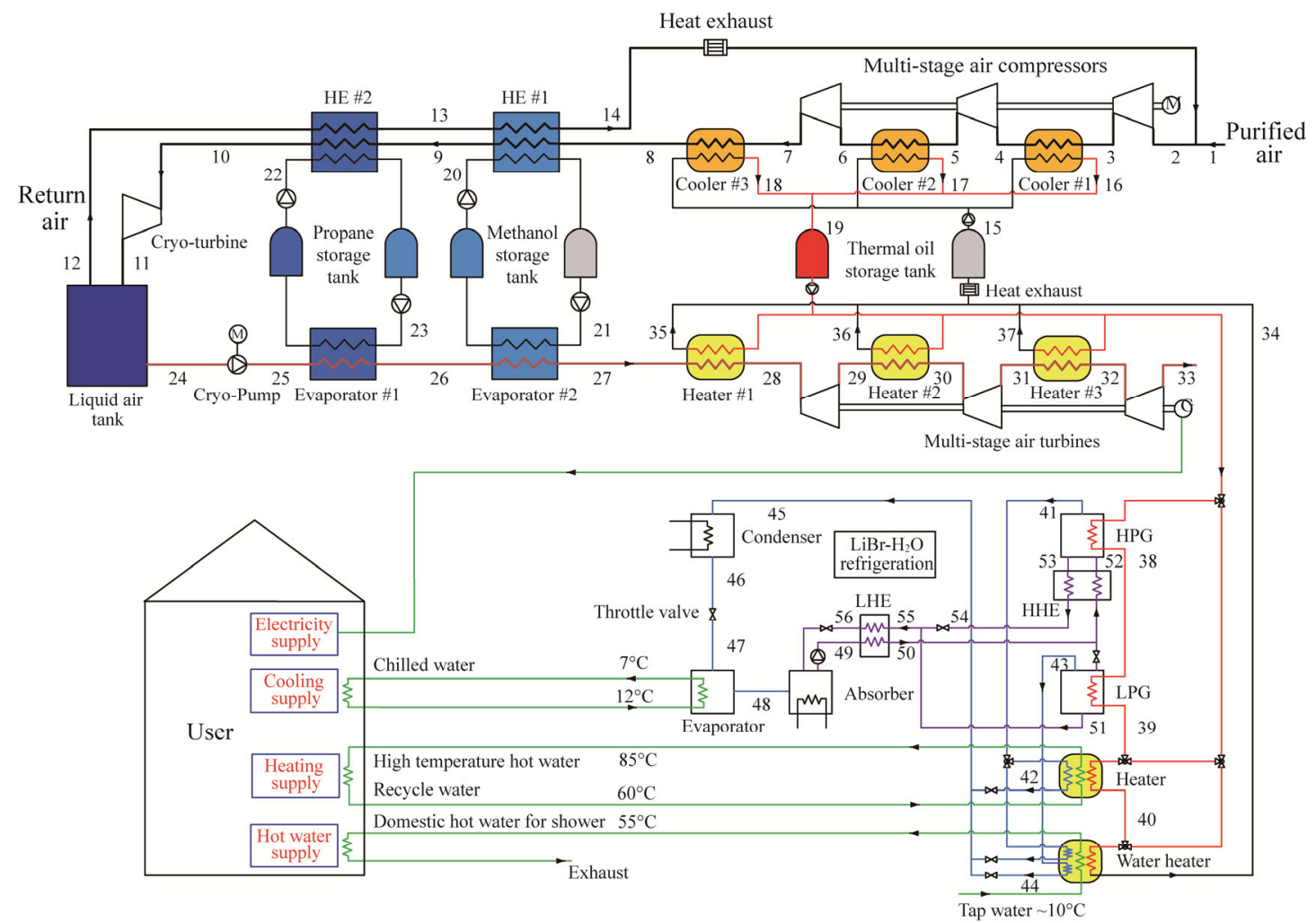

(b) Flow diagram

Fig. 2 The proposed hybrid LAES for cooling, heating, hot water and power supply 
(These temperature numbers are taken based on practical applications). It should be noted that the high-pressure water vapor (State 41) leaving the high-pressure generator (HPG) flows into either the heater or the water heater through three-way valves to provide heating or domestic hot water, rather than goes to the low-pressure generator (LPG). This is because it has a lower condensing temperature $\left(\sim 90^{\circ} \mathrm{C}\right)$, which is much lower than the thermal oil temperature $\left(\sim 180^{\circ} \mathrm{C}\right)$. In addition, the low-pressure water vapor (State 43) leaving the LPG still carries low-grade heat and is used for domestic hot water.

Demands for hot water and power are inevitable for almost all the end users, whereas heating and cooling requirements are optional in many cases. Therefore, to meet different end-user demands in the UK, we consider the following three operation (working) modes for the hybrid LAES, as illustrated in Fig. 3:

(1) Power, Hot water and Cooling supply in summer (PHC mode);

(2) Power, Hot water and Heating supply in winter (PHH mode);

(3) Power and Hot water supply in spring or autumn (PH mode).

In the PHC mode, the excess heat is carried by the hot thermal oil (State 19) flowing in turn through the HPG, the LPG and the water heater. Both the high-pressure water vapor (State 41) generated in the HPG and the lowpressure water vapor (State 43) generated in the LPG transfer their heat to the tap water in the water heater (for domestic hot water supply) before being throttled to the same condensing pressure (State 45), and subsequently flowing through the condenser and the throttle valve, and finally arriving at the evaporator to produce chilled water $\left(7^{\circ} \mathrm{C}\right)$ for cooling. The hot thermal oil (State 39$)$ leaving the LPG enters the water heater where it transfers the heat energy to the tap water to produce domestic hot water.

In the PHH mode, the excess heat is carried by the hot thermal oil (State 19) flowing through the heater first to heat the recirculating water $\left(60^{\circ} \mathrm{C}\right)$ for space heating, and then the water heater to heat the tap water for domestic hot water supply.

In the PH mode, the excess heat is carried by the hot thermal oil (State 19), which flows through the water heater to heat the tap water to produce domestic hot water.

\subsection{Thermodynamic models}

\subsubsection{The charging and discharging processes}

In the charging process of the hybrid LAES system, ambient air is purified first to remove moisture, carbon dioxide and particulate matters before compression by the multi-stage air compressors. The power consumption of air compression, $W_{\text {com }}$, can be calculated by:

$$
W_{\text {com }}=\frac{m_{\mathrm{air}, \mathrm{ch}} \cdot\left[\left(h_{3, \mathrm{~s}}-h_{2}\right)+\left(h_{5, \mathrm{~s}}-h_{4}\right)+\left(h_{7, \mathrm{~s}}-h_{6}\right)\right]}{\eta_{\text {com }}}
$$

where $m_{\text {air,ch }}$ is the mass flow rate of air in the multi-stage air compressors; $h_{i}$ represents the specific enthalpy with $i$ corresponding to state $i$ shown in Fig. $2 ; \eta_{\text {com }}$ is the isentropic efficiency of air compressors; subscript $\mathrm{s}$ indicates an isentropic process.

For off-the-shelf products, screw compressors are widely used in industry for working pressures lower than $\sim 2 \mathrm{MPa}$ due to reliability and low maintenance costs, whereas piston compressors are for high pressure applications from $\sim 3$ to $\sim 40 \mathrm{MPa}$ [29]; see Fig. 4 . The
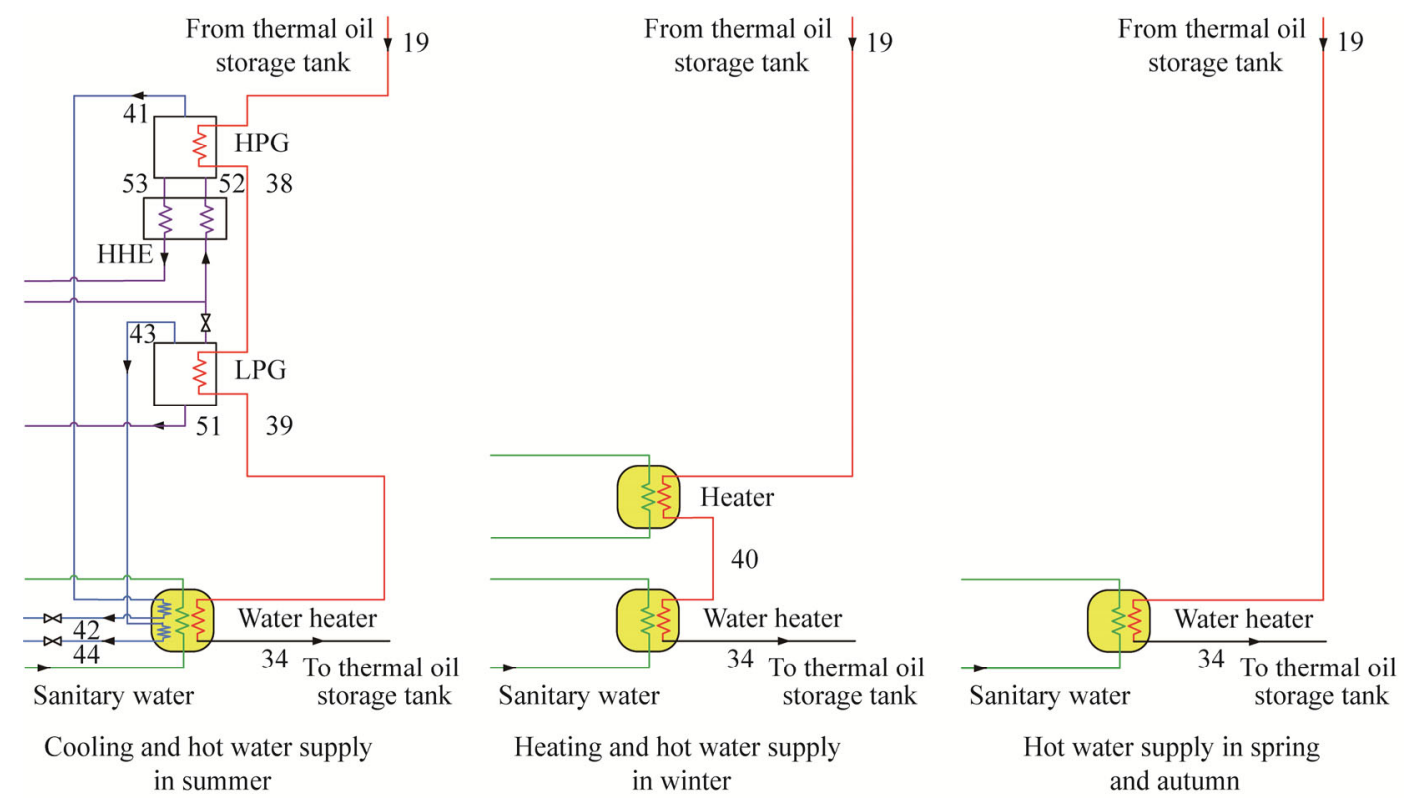

Fig. 3 Three working modes of the hybrid LAES for meeting end-user demands in the UK 
screw compressors have an isentropic efficiency of 0.65 to 0.7 and the isentropic efficiency of piston compressors lies between 0.8 and 0.9 [30]. As a result, the selection of the compressors is shown in Table 1.

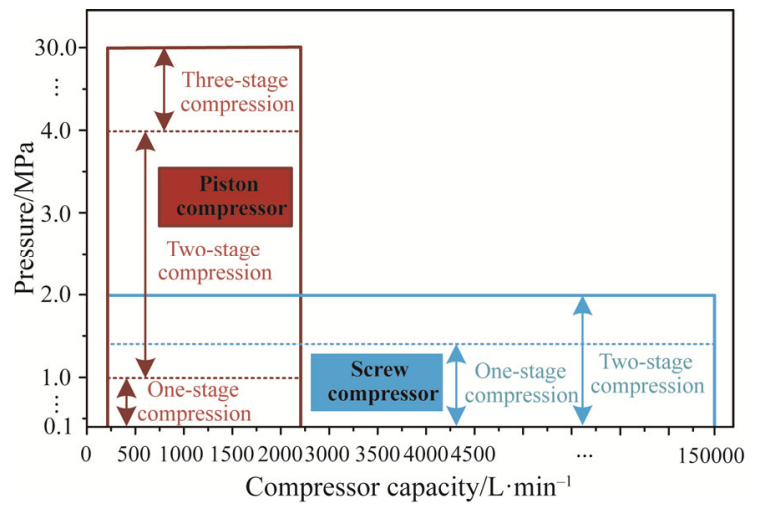

Fig. 4 Screw and piston compressors: capacity and working pressure

Table 1 Selections of air compressor type [29] and efficiency [30]

\begin{tabular}{cccc}
\hline $\begin{array}{c}\text { Charging } \\
\text { pressure/MPa }\end{array}$ & $\begin{array}{c}\text { Compression } \\
\text { stages }\end{array}$ & $\begin{array}{c}\text { Compressor } \\
\text { type }\end{array}$ & $\begin{array}{c}\text { Isentropic } \\
\text { efficiency }\end{array}$ \\
\hline$P_{\mathrm{ch}} \leqq 2$ & 2 & Screw & 0.68 \\
$2<P_{\mathrm{ch}} \leqq 4$ & 2 & Piston & 0.89 \\
$P_{\mathrm{ch}}>4$ & 3 & Piston & 0.89 \\
\hline
\end{tabular}

The compressed air (State 8) is cooled in turn via heat exchangers HE \#1 and HE \#2. The air parameters at the outlet of the HE \#1 and HE \#2 are determined via energy conservation and pinch point constraints:

$$
\begin{aligned}
& h_{9}=h_{8}-\frac{m_{\text {methanol,ch }} \cdot\left(h_{21}-h_{20}\right)+m_{12} \cdot\left(h_{14}-h_{13}\right)}{m_{\text {air,ch }}} \\
& h_{10}=h_{9}-\frac{m_{\text {propane,ch }} \cdot\left(h_{23}-h_{22}\right)+m_{12} \cdot\left(h_{13}-h_{12}\right)}{m_{\text {air,ch }}}
\end{aligned}
$$

where $m_{\text {methanol,ch }}$ and $m_{\text {propane,ch }}$ are the mass flow rates of methanol and propane in the charging process, respectively.

The low-temperature compressed air (State 10) expands in the cryo-turbine with part of the air liquefied. The power generated by the cryo-turbine $\left(W_{\text {cry-tur }}\right)$ and the liquid air yield $(Y)$ are given respectively by:

$$
\begin{gathered}
W_{\text {cry-tur }}=m_{\text {air,ch }} \cdot \eta_{\text {cry-tur }} \cdot\left(h_{10}-h_{11, \mathrm{~s}}\right) \\
Y=\frac{m_{\text {air,ch }}-m_{12}}{m_{\text {air,ch }}}
\end{gathered}
$$

where $\eta_{\text {cry-tur }}$ is the isentropic efficiency of the cryo-turbine.

During peak times, the stored liquid air is pumped to a high pressure by a cryo-pump. The power consumption of the cryo-pump, $W_{\text {pump }}$, is calculated by:

$$
W_{\text {pump }}=\frac{m_{\text {air,dis }} \cdot\left(h_{25, \mathrm{~s}}-h_{24}\right)}{\eta_{\text {pump }}}
$$

where $\eta_{\text {pump }}$ is the isentropic efficiency of the cryo-pump; $m_{\text {air,dis }}$ is the mass flow rate of liquid air in the discharging cycle.

The low-temperature liquid air (State 25) transfers cold energy in turn to propane and methanol via the evaporator \#1 and evaporator \#2. The air outlet conditions can be determined by energy conservation and pinch point constraints:

$$
\begin{aligned}
& h_{26}=h_{25}+\frac{m_{\text {propane,dis }} \cdot\left(h_{23}-h_{22}\right)}{m_{\text {air,dis }}} \\
& h_{27}=h_{26}+\frac{m_{\text {methanol,dis }} \cdot\left(h_{21}-h_{20}\right)}{m_{\text {air,dis }}}
\end{aligned}
$$

where $m_{\text {methanol,dis }}$ and $m_{\text {propane,dis }}$ are the mass flow rates of methanol and propane in the discharging process, respectively.

The high-pressure air (State 27) is preheated by the hot thermal oil stored during air compression in the charging process before entering the multi-stage air turbine to generate electricity. The power generated by the air turbines, $W_{\text {tur, }}$ can be calculated by:

$$
\begin{aligned}
W_{\text {tur }}= & m_{\text {air,dis }} \cdot \eta_{\text {tur }} \cdot\left[\left(h_{28}-h_{29, \mathrm{~s}}\right)\right. \\
& \left.+\left(h_{30}-h_{31, \mathrm{~s}}\right)+\left(h_{32}-h_{33, \mathrm{~s}}\right)\right]
\end{aligned}
$$

where $\eta_{\text {tur }}$ is the isentropic efficiency of the air turbines.

\subsubsection{The $\mathrm{LiBr}-\mathrm{H}_{2} \mathrm{O}$ refrigeration cycle}

For the double-effect $\mathrm{LiBr}-\mathrm{H}_{2} \mathrm{O}$ refrigeration cycle, the following assumptions are made to analyze the cycle performance:

(1) Strong solutions (States 51 and 53) leaving the HPG and LPG are saturated; weak solution leaving the absorber is saturated;

(2) The highest solution concentration leaving the HPG and LPG is set at 0.64 to avoid crystallization in pipelines; and the pump work is negligible in the cycle;

(3) Refrigerant (water) is saturated at the outlet of the condenser and evaporator, and experiences an isenthalpic process in the throttle valve.

For the HPG and LPG, the excess heat carried by the hot thermal oil is used to heat the weak solution for generating water vapor. The heat loads of the HPG $\left(Q_{\mathrm{HPG}}\right)$ and LPG $\left(Q_{\mathrm{LPG}}\right)$ are respectively calculated by the following energy conservation equations:

$$
\begin{gathered}
Q_{\mathrm{HPG}}=m_{53} \cdot h_{53}+m_{41} \cdot h_{41}-m_{52} \cdot h_{52} \\
Q_{\mathrm{LPG}}=m_{51} \cdot h_{51}+m_{43} \cdot h_{43}-\left(m_{50}-m_{52}\right) \cdot h_{50}
\end{gathered}
$$

where $m_{50}, m_{51}, m_{52}$ and $m_{53}$ are the mass flow rates of the $\mathrm{LiBr}$ aqueous solution at different states; $m_{41}$ and $m_{43}$ are the mass flow rates of the water vapor generated in the HPG and LPG, respectively. Based on mass conservation 
in the HPG and LPG, one has:

$$
\begin{gathered}
m_{41}=m_{52}-m_{53} \\
m_{43}=\left(m_{50}-m_{52}\right)-m_{51}
\end{gathered}
$$

The water vapor generated in the HPG and LPG is condensed and combined. The mass flow rates of the refrigerant (water), $m_{\mathrm{w}}$, in the condenser, evaporator and the absorber are given by:

$$
m_{\mathrm{w}}=m_{41}+m_{43}
$$

The saturated liquid water at the outlet of the condenser is throttled to the evaporating pressure before entering the evaporator to produce chilled water for cooling. The cooling capacity of the evaporator, $Q_{\text {eva }}$, is determined by:

$$
Q_{\text {eva }}=m_{\mathrm{w}} \cdot\left(h_{48}-h_{47}\right)
$$

The saturated water vapor in the evaporator is absorbed by the strong solution in the absorber. The mass and energy conservation of the absorber gives:

$$
\begin{gathered}
m_{49}=m_{\mathrm{w}}+m_{56} \\
Q_{\mathrm{abs}}=m_{56} \cdot h_{56}+m_{\mathrm{w}} \cdot h_{48}-m_{49} \cdot h_{49}
\end{gathered}
$$

where $Q_{\text {abs }}$ is the heat released in the absorber.

\subsubsection{The district cooling, heating and hot water network}

The hybrid LAES system could supply cooling, heating and hot water for the decentralized energy network by consuming the excess heat as mentioned above. The thermal loss ( $\left.\eta_{\text {loss }}\right)$ due to the district energy network is selected as $5 \%$ of the energy supplied by the hybrid LAES system [31].

In the PHC mode, there is no heating. The hot water capacity $\left(Q_{\mathrm{h} \text {-water }}\right)$ and cooling capacity $\left(Q_{\text {cool }}\right)$ are obtained as:

$$
\begin{gathered}
Q_{\text {cool }}=\left(1-\eta_{\text {loss }}\right) \cdot Q_{\text {eva }} \\
Q_{\text {h-water }}=\left(1-\eta_{\text {loss }}\right) \cdot\left[m_{41} \cdot\left(h_{41}-h_{42}\right)\right. \\
\left.+m_{43} \cdot\left(h_{43}-h_{44}\right)+m_{\text {oil }} \cdot\left(h_{39}-h_{34}\right)\right]
\end{gathered}
$$

where $m_{\mathrm{oil}}$ is the mass flow rate of the excess heat carrying thermal oil.

In the PHH mode, heating capacity $\left(Q_{\text {heat }}\right)$ and hot water capacity $\left(Q_{\mathrm{h} \text {-water }}\right)$ are required by end-users:

$$
\begin{aligned}
Q_{\text {heat }} & =\left(1-\eta_{\text {loss }}\right) \cdot m_{\text {oil }} \cdot\left(h_{19}-h_{40}\right) \\
Q_{\text {h-water }} & =\left(1-\eta_{\text {loss }}\right) \cdot m_{\text {oil }} \cdot\left(h_{40}-h_{34}\right)
\end{aligned}
$$

In the PH mode, only hot water is in demand. Hence, the hot water capacity $\left(Q_{\mathrm{h} \text {-water }}\right)$ is determined by:

$$
Q_{\text {h-water }}=\left(1-\eta_{\text {loss }}\right) \cdot m_{\text {oil }} \cdot\left(h_{19}-h_{34}\right)
$$

\subsubsection{Equivalent electricity production}

As the excess heat in the hybrid LAES system is used for providing different commodities (cooling, heating and hot water) for decentralized energy network, it is necessary to convert the different commodities into equivalent electricity production, for evaluating the nominal-electrical round trip efficiency in the next section.

Fig. 5 shows the general ways to obtain cooling, heating and hot water in the UK. At the moment, cooling is usually achieved by mechanical chillers; hot water and heating are provided through gas boilers. However, UK is promoting the application of air-source heat pumps for heating or hot water as potential technologies for heat decarbonization by 2050 . To evaluate the equivalent electrical consumed by the end-users with the above ways, several assumptions are made as follows.

Gas boiler (condensing type) consumes natural gas to provide heating or hot water, which has a thermal efficiency $\left(\eta_{\text {gas,ther }}\right)$ of $90 \%$ [32]. As the consumed natural gas is used for generating electricity in a combined gas turbine power plant, the thermal-to-electricity efficiency $\left(\eta_{\text {gas,ele }}\right)$ is $50 \%$ [33].

The reversible air-source heat pump produces cooling at $7^{\circ} \mathrm{C}$ in summer with $\mathrm{R} 410 \mathrm{~A}$ as the refrigerant and screw-type compressors; in winter, it works reversely to provide heating or hot water at $55^{\circ} \mathrm{C}$; the cooling $\left(\mathrm{COP}_{\mathrm{c}}\right)$ and heating $\left(\mathrm{COP}_{\mathrm{h}}\right)$ performances of the reversible air-source heat pump are selected as 4.18 and 3.06, respectively (see discussions in the following).

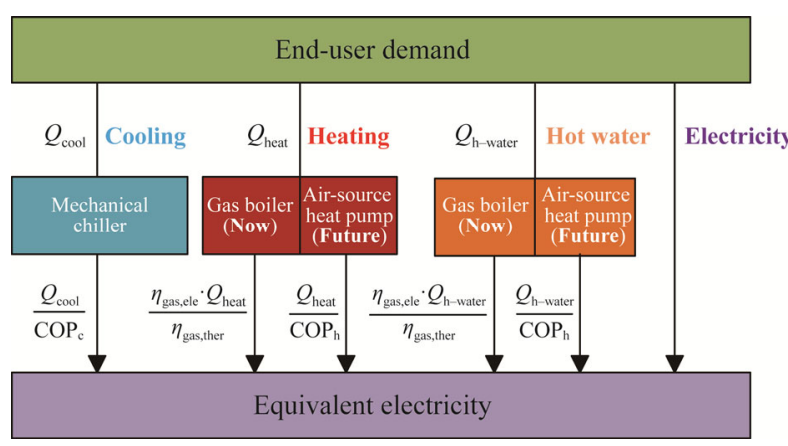

Fig. 5 The general ways to obtain cooling, heating and hot water in the UK, and equivalent electricity calculations

For the reversible air-source heat pump, the $\mathrm{COP}_{\mathrm{c}}$ and $\mathrm{COP}_{\mathrm{h}}$ are calculated as follows,

$$
\begin{gathered}
W_{\text {ref,com }}=m_{\text {ref }} \cdot \frac{h_{\text {com,out,s }}-h_{\text {com }, \text { in }}}{\eta_{\text {ref,com }}} \\
\eta_{\text {ref,com }}=0.07551+0.28995 \cdot r-0.04521 \cdot r^{2} \\
+0.00279 \cdot r^{3}-6.34 \times 10^{-5} \cdot r^{4} \\
\mathrm{COP}_{\mathrm{c}}=\frac{Q_{\text {cool }}}{W_{\text {ref,com }}} \\
\mathrm{COP}_{\mathrm{h}}=\frac{Q_{\text {heat }}}{W_{\text {ref,com }}}
\end{gathered}
$$

where $m_{\text {ref }}$ is the mass flow rate of the refrigerant; $\eta_{\text {ref,com }}$ is the isentropic efficiency of the refrigeration com- 
pressor (screw type) and is calculated based on the pressure ratio $(r)$ between the outlet and inlet of the refrigeration compressor [34].

Fig. 6 shows the cooling and heating performance of the reversible air-source heat pump under the climate conditions of London, UK in 2018. It can be seen that the $\mathrm{COP}_{\mathrm{c}}$ in summer is at 4.18 and the $\mathrm{COP}_{\mathrm{h}}$ in winter varies between 2.94 and 3.17 with an average at 3.06, which is mainly affected by the weather conditions.

In the current case with gas boilers for heating or hot water, the equivalent electricity production of different commodities (cooling, heating and hot water) is defined as:

$$
W_{\text {eqv,gas }}=\frac{Q_{\text {cool }}}{\operatorname{COP}_{\mathrm{c}}}+\frac{\eta_{\text {gas,ele }} \cdot Q_{\text {heat }}}{\eta_{\text {gas, ther }}}+\frac{\eta_{\text {gas,ele }} \cdot Q_{\mathrm{h} \text {-water }}}{\eta_{\text {gas,ther }}}
$$

As air source heat pumps are used for heating or hot water in the UK in the future, the equivalent electricity production of different commodities (heating and hot water) is calculated by:

$$
W_{\text {eqv,hp }}=\frac{Q_{\text {cool }}}{\mathrm{COP}_{\mathrm{c}}}+\frac{Q_{\text {heat }}}{\mathrm{COP}_{\mathrm{h}}}+\frac{Q_{\mathrm{h}-\text { water }}}{\mathrm{COP}_{\mathrm{h}}}
$$

\subsection{Performance indexes}

\subsubsection{Electrical round trip efficiency}

For the baseline LAES, electricity is stored in the form of liquid air at off-peak times, and the stored liquid air is used to generate electricity at peak times. Therefore, the electrical round trip efficiency of the baseline LAES, $\eta_{\text {E_RTE }}$, is defined as the ratio of net power generation at peak times to net power consumption at off-peak times:

$$
\eta_{\text {E_RTE }}=\frac{\left(W_{\text {tur }}-W_{\text {pump }}\right) \cdot t_{\text {dis }}}{\left(W_{\text {com }}-W_{\text {cry-tur }}\right) \cdot t_{\text {ch }}}
$$

where $t_{\mathrm{ch}}$ and $t_{\mathrm{dis}}$ are the charging and discharging time, respectively.

\subsubsection{Maximum electrical round trip efficiency}

The hybrid LAES system generates not only electricity at peak times, but also excess heat (stored in thermal oil) that cannot be fully used for power generation. Therefore, considering the excess heat, the maximum electrical round trip efficiency (i.e., exergy efficiency) of the hybrid LAES system, $\eta_{\text {E_RTE_max, }}$ is defined as:

$$
\eta_{\text {E_RTE_max }}=\frac{\left(W_{\text {tur }}-W_{\text {pump }}\right) \cdot t_{\text {dis }}+m_{\text {oil }} \cdot e x_{\text {heat }} \cdot t_{\text {dis }}}{\left(W_{\text {com }}-W_{\text {cry-tur }}\right) \cdot t_{\text {ch }}}
$$

where $e x_{\text {heat }}$ is the specific exergy of the excess heat, and can be calculated by,

$$
e x_{\text {heat }}=\left(h_{19}-h_{\mathrm{amb}}\right)-T_{\mathrm{amb}} \cdot\left(s_{19}-s_{\mathrm{amb}}\right)
$$

\subsubsection{Nominal-electrical round trip efficiency}

For the hybrid LAES system, the nominal-electrical round trip efficiency (neRTE) is defined as the ratio of the total power generation at peak times (net power generation by turbines plus equivalent electricity production by different commodities) to the net power consumption at off-peak times.

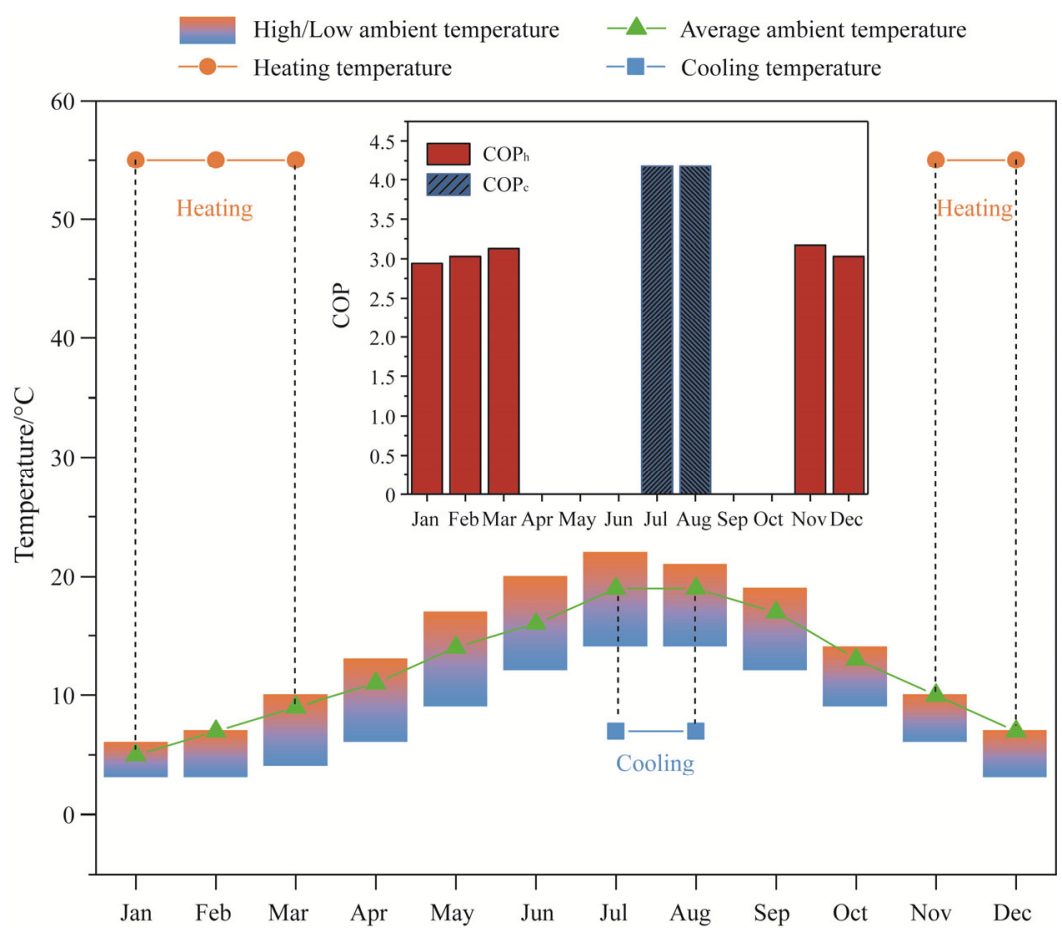

Fig. 6 Cooling performance in summer and heating performance in winter of the reversible air-source heat pump in London, UK 
For the current case of end-users using gas boilers for heating or hot water in the UK, the neRTE of the hybrid LAES system, $\eta_{\mathrm{NE} \_\mathrm{RTE}}$, is defined as:

$$
\eta_{\mathrm{NE} \_\mathrm{RTE}}=\frac{\left(W_{\text {tur }}-W_{\text {pump }}\right) \cdot t_{\text {dis }}+W_{\text {eqv }, \mathrm{gas}} \cdot t_{\mathrm{dis}}}{\left(W_{\text {com }}-W_{\text {cry-tur }}\right) \cdot t_{\mathrm{ch}}}
$$

For the future case where end-users use air-source heat pumps for heating or hot water, the neRTE of the hybrid LAES is given as:

$$
\eta_{\mathrm{NE} \_ \text {RTE }}=\frac{\left(W_{\text {tur }}-W_{\text {pump }}\right) \cdot t_{\text {dis }}+W_{\text {eqv, hp }} \cdot t_{\text {dis }}}{\left(W_{\text {com }}-W_{\text {cry-tur }}\right) \cdot t_{\text {ch }}}
$$

\subsubsection{Primary energy savings}

The hybrid LAES system stores excess (off-peak) electricity from national grid, and then provides polygeneration for end-users at peak times, saving primary energy consumptions (natural gas is assumed as the primary energy here).

For the current case with gas boilers for heating or hot water in the UK, the primary energy savings of the hybrid LAES system is defined as:

$$
E_{\mathrm{PES}}=\frac{\left[\left(W_{\text {tur }}-W_{\text {pump }}\right)+W_{\text {eqv,gas }}\right] \cdot t_{\text {dis }}}{\eta_{\text {gas,ele }}}
$$

For the future heating with air source heat pumps in winter, the primary energy savings of the hybrid LAES system is calculated by:

$$
E_{\mathrm{PES}}=\frac{\left[\left(W_{\text {tur }}-W_{\text {pump }}\right)+W_{\text {eqv,hp }}\right] \cdot t_{\text {dis }}}{\eta_{\text {gas,ele }}}
$$

\subsubsection{Avoided carbon dioxide emissions}

The hybrid LAES system contributes to primary energy savings as mentioned above, which avoids carbon dioxide emissions caused by the primary energy. For the current case with gas boilers in the UK, the amount of avoided carbon dioxide emissions by the hybrid LAES system is defined as:

$$
M_{\mathrm{CO}_{2}}=\xi \cdot\left[\left(W_{\text {tur }}-W_{\text {pump }}\right)+W_{\text {eqv,gas }}\right] \cdot t_{\text {dis }}
$$

For the future heating in winter with air source heat pumps, the amount of avoided carbon dioxide emissions by the hybrid LAES system is given as:

$$
M_{\mathrm{CO}_{2}}=\xi \cdot\left[\left(W_{\text {tur }}-W_{\text {pump }}\right)+W_{\text {eqv,hp }}\right] \cdot t_{\text {dis }}
$$

where $\xi$ is the emission factor, representing carbon dioxide emissions by a typical electricity mix, and is selected as $0.38 \mathrm{~kg}-\mathrm{CO}_{2} / \mathrm{kWh}$ [35].

\section{Results and Discussion}

The default parameters used for the hybrid LAES system are listed in Table 2. The charging time for air liquefaction at off-peak times is set as $8 \mathrm{~h} / \mathrm{d}$ and the liquid air is stored at $0.1 \mathrm{MPa}$; the discharging time for the power recovery process at peak times is set as $4 \mathrm{~h} / \mathrm{d}$; and the discharging pressure is set at $12 \mathrm{MPa}$ considering that a higher inlet pressure of air turbines would generate more power. The purified air in the charging process is assumed to consist of nitrogen $(78.12 \%)$, oxygen $(20.96 \%)$ and $\operatorname{argon}(0.92 \%)$. The Dowtherm $\mathrm{G}$ is chosen as the thermal oil and its properties are obtained from the ASPEN plus 8.8 software package. The properties of the purified air, propane and methanol are obtained from the REFPROP 9.0. The vapor pressure and enthalpy of the $\mathrm{LiBr}-\mathrm{H}_{2} \mathrm{O}$ solution are obtained from Pátek and Klomfar [36] and Talbi and Agnew [37], respectively. The models are solved in the MATLAB environment.

Table 2 Working parameters of the hybrid LAES system

\begin{tabular}{cc}
\hline Ambient pressure $/ \mathrm{MPa}$ & 0.1 \\
Ambient temperature $/ \mathrm{K}$ & 293 \\
Charging time $t_{\mathrm{ch}} / \mathrm{h} \cdot \mathrm{d}^{-1}$ & 8 \\
Liquid air storage pressure $P_{24} / \mathrm{MPa}$ & 0.1 \\
Discharging pressure $P_{25} / \mathrm{MPa}$ & 12 \\
Discharging time $t_{\mathrm{dis}} / \mathrm{h} \cdot \mathrm{d}^{-1}$ & 4 \\
Thermal oil storage temperature $T_{15} / \mathrm{K}$ & 293 \\
Methanol storage temperature $T_{21} / \mathrm{K}$ & 293 \\
Propane storage temperature $T_{23} / \mathrm{K}$ & 214 \\
Temperature difference at pinch point in evaporators $/ \mathrm{K}$ & 2 \\
Temperature difference at pinch point in $\mathrm{HEs}, \mathrm{heaters}$ & 5 \\
and coolers/K & 0.9 \\
Isentropic efficiency of air turbines & 0.8 \\
Isentropic efficiency of cryo-turbine & 0.7 \\
Isentropic efficiency of cryo-pump & 298 \\
Minimum usable temperature of hot thermal oil/K & 278 \\
Evaporating temperature in the evaporator/K & 308 \\
Absorbing temperature in the absorber/K & 308 \\
\hline
\end{tabular}

Table 3 shows the representative performance of the hybrid LAES system, where both the charging and discharging pressure are at $12 \mathrm{MPa}$. With a given power consumption of $8 \mathrm{MWh}(1 \mathrm{MW} \times 8 \mathrm{~h})$ in the charging process at off-peak times, the hybrid LAES system provides 4.4 MWh peak electricity and 2.64 MWh excess thermal energy available for heating and cooling applications; the maximum electrical round trip efficiency (i.e., exergy efficiency) reaches 0.64 with the contribution of the excess thermal energy.

\subsection{Performance of the baseline LAES over a wide range of charging pressure}

In the charging process, the purified air is compressed 
to a high pressure (the charging pressure), and is then cooled down for air liquefaction. The compressed air requires different cooling capacities under different charging pressures as shown in Fig. 7. When the charging pressure is below the critical pressure of the air (3.85 $\mathrm{MPa}$ ), there is a phase change as the air is cooled to its dew point, which requires more cold energy. Therefore, the performance of the baseline LAES at a charging pressure below the critical point will differ from that above the critical pressure.

Table 3 Representative performance of the hybrid LAES system

\begin{tabular}{|c|c|c|c|}
\hline Results & PHC & $\mathrm{PHH}$ & $\mathrm{PH}$ \\
\hline $\begin{array}{l}\text { Electricity consumption during } \\
\text { charging/MWh }\end{array}$ & 8 & 8 & 8 \\
\hline $\begin{array}{c}\text { Electricity generation during } \\
\text { discharging/MWh }\end{array}$ & 4.40 & 4.40 & 4.40 \\
\hline Electrical round trip efficiency & 0.55 & 0.55 & 0.55 \\
\hline Cold energy stored/MWh & 3.73 & 3.73 & 3.73 \\
\hline Thermal energy stored/MWh & 5.86 & 5.86 & 5.86 \\
\hline $\begin{array}{l}\text { Thermal energy available for other } \\
\text { applications/MWh }\end{array}$ & 2.64 & 2.64 & 2.64 \\
\hline $\begin{array}{c}\text { Maximum electrical round trip } \\
\text { efficiency }\end{array}$ & 0.64 & 0.64 & 0.64 \\
\hline $\begin{array}{l}\text { Thermal energy available for heating } \\
\qquad\left(85^{\circ} \mathrm{C}\right) / \mathrm{MWh}\end{array}$ & 0 & 2.10 & 2.64 \\
\hline $\begin{array}{l}\text { Thermal energy available for hot } \\
\text { water }\left(55^{\circ} \mathrm{C}\right) / \mathrm{MWh}\end{array}$ & 1.94 & 0.54 & 0 \\
\hline $\begin{array}{l}\text { Thermal energy available for cooling } \\
\left(7^{\circ} \mathrm{C}\right) / \mathrm{MWh}\end{array}$ & 0.70 & 0 & 0 \\
\hline
\end{tabular}

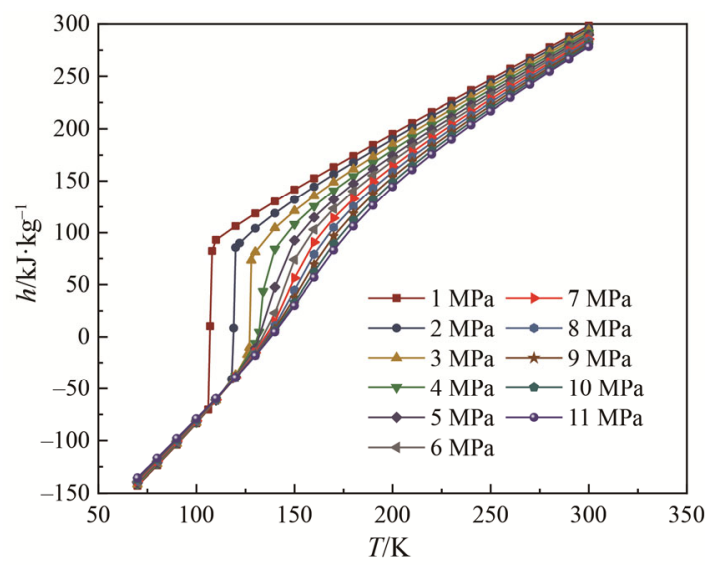

Fig. 7 Properties of compressed air under different charging pressures

Fig. 8 shows how the charging pressure affects the liquid air yield for the baseline LAES system operated between 1 and $21 \mathrm{MPa}$. The liquid air yield is seen to increase significantly first from 0.214 to 0.432 with the charging pressure rising from 1 to $4 \mathrm{MPa}$, which is mainly due to a significant decrease in the cooling capacity required for air liquefaction as shown in Fig. 7. It then increases gradually from 0.432 to 0.885 as the charging pressure increases from 4 to $19 \mathrm{MPa}$ due to a gradual decrease in the required cooling capacity (see Fig. 7). Finally, the liquid air yield is seen to stabilize at 0.885 when the charging pressure goes above $19 \mathrm{MPa}$ mainly because a further increase in the charging pressure has little effect on the cooling capacity required for air liquefaction.

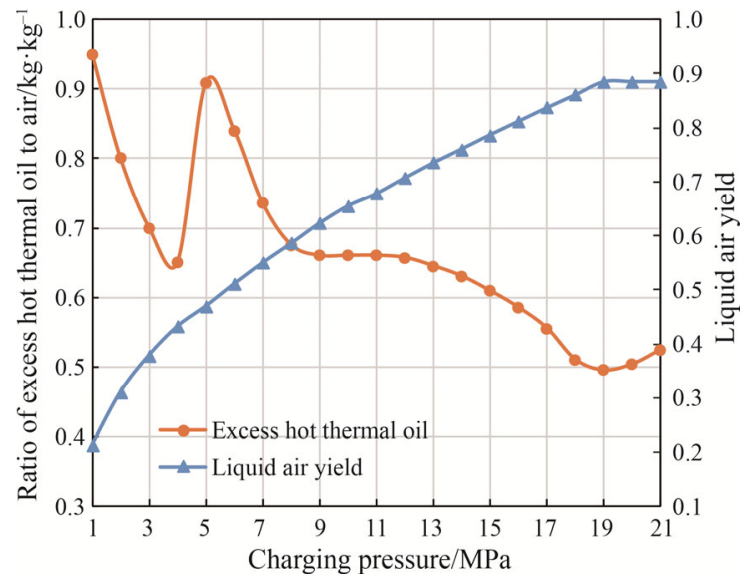

Fig. 8 Effect of charging pressure on the excess compression heat (expressed as the ratio of the hot thermal oil mass to the air mass) and liquid air yield for the baseline LAES

Fig. 8 also shows the effect of the charging pressure on the production of excess compression heat, which is expressed as the mass ratio of the excess hot thermal oil to the compressed air in the charging process. The reason for using such a ratio is because the amount of hot thermal oil produced during air compression is proportional to the amount of compressed air. With a given compressed air mass flow rate in the charging process, a higher charging pressure not only leads to more generation of compression heat (i.e. more hot thermal oil stored), but also produces more liquid air which consumes more compression heat to heat it up for generating power in the discharging process. Finally, the net stored compression heat (i.e. excess thermal oil) will fluctuate depending on the charging pressure. One can see that the excess hot thermal oil to compressed air mass ratio decreases dramatically from 0.95 to 0.65 when the charging pressure increases from 1 to $4 \mathrm{MPa}$. This is mainly due to the significant increase of liquid air yield, leading to an increased consumption of hot thermal oil in the discharging process. The mass ratio increases significantly from 0.65 to 0.91 when the charging pressure increases from 4 to $5 \mathrm{MPa}$. This is mainly because a three-stage compression is used in this case (see Table 1), which produces more hot thermal oil in the charging process. As the charging pressure rises from 5 to $9 \mathrm{MPa}$, the mass ratio decreases dramatically from 0.91 
to 0.66 , mainly due to the significant increase in the liquid air yield. The mass ratio is stabilized at $\sim 0.66$ when the charging pressure increases from 9 to $12 \mathrm{MPa}$, which can be explained as a balance has been reached between the increasing hot thermal oil consumption in the discharging process and the increasing hot thermal oil generation in the charging process. The mass ratio is seen to decrease from 0.66 to 0.5 when the charging pressure increases from 12 to $19 \mathrm{MPa}$, due to an increased liquid air yield. As the charging pressure increases above 19 $\mathrm{MPa}$, the mass ratio shows a gradual increase, which can be explained by the fact that the amount of hot thermal oil generated in the charging cycle increases but the liquid air yield remains stable. In summary, the baseline LAES has a lower liquid air yield, but produces more excess heat at low charging pressures of 1 to $7 \mathrm{MPa}$.

The effect of the charging pressure on the performance of the baseline LAES is shown in Fig. 9 with the air flow rate at $2 \mathrm{~kg} / \mathrm{s}$ in the charging process. Fig. 9(a) plots the power consumption of compressors, power generation of turbines, and the amount of excess heat generated under different charging pressures. The power consumption is seen increasing significantly from 4.93 to $7 \mathrm{MWh}$ as the charging pressure rises from 1 to $2 \mathrm{MPa}$. There is a decrease in the power consumption to $6.18 \mathrm{MWh}$ with a further increase of the charging pressure from 2 to $3 \mathrm{MPa}$. This is because piston compressors with a higher isentropic efficiency are selected for charging pressures above $2 \mathrm{MPa}$; see Table 1 . When the charging pressure increases further from 4 to $5 \mathrm{MPa}$, the power consumption of air compressors decreases slightly from 7 to 6.83 MWh due to the three-stage compression process being chosen at a charging pressure above $4 \mathrm{MPa}$ (see Table 1). At a charging pressure above $5 \mathrm{MPa}$, a gradual increase in the power consumption of air compressors occurs with increasing the charging pressure. Fig. 9(a) indicates the amount of power generation by air turbines increases significantly from 1.32 to $6.41 \mathrm{MWh}$ when the charging pressure increases from 1 to $19 \mathrm{MPa}$. This is clearly due to the significant increase in the liquid air yield over the charging pressure range as shown in Fig. 8. There is a slight increase in the amount of power generation from 6.41 to $6.52 \mathrm{MWh}$ with a further increase of the charging pressure from 19 to $21 \mathrm{MPa}$, which is mainly due to increased temperature of the hot thermal oil while the liquid air yield remains unchanged. Fig. 9(a) also shows that the excess compression heat carried by the hot thermal oil decreases from 4.94 to $2.34 \mathrm{MWh}$ with the charging pressure increasing from 1 to $21 \mathrm{MPa}$.

Fig. 9(b) shows the effect of the charging pressure on the eRTE for the baseline LAES with and without the consideration of excess heat. For the case without excess heat, a dramatic increase occurs in the eRTE from $26.7 \%$ to $41.1 \%$ when the charging pressure increases from 1 to
$3 \mathrm{MPa}$. This is clearly due to the significant increase in the liquid air yield over the pressure range. A slow rate of increase in the eRTE is seen with a further increase in the charging pressure from 3 to $19 \mathrm{MPa}$. The eRTE at 19 $\mathrm{MPa}$ reaches $61.7 \%$. However, a further increase in the charging pressure from 19 to $21 \mathrm{MPa}$ shows a decrease in the eRTE from $61.7 \%$ to $60.8 \%$. This is mainly due to the increased power consumption of air compressors in the charging process when the liquid air yield remains unchanged.
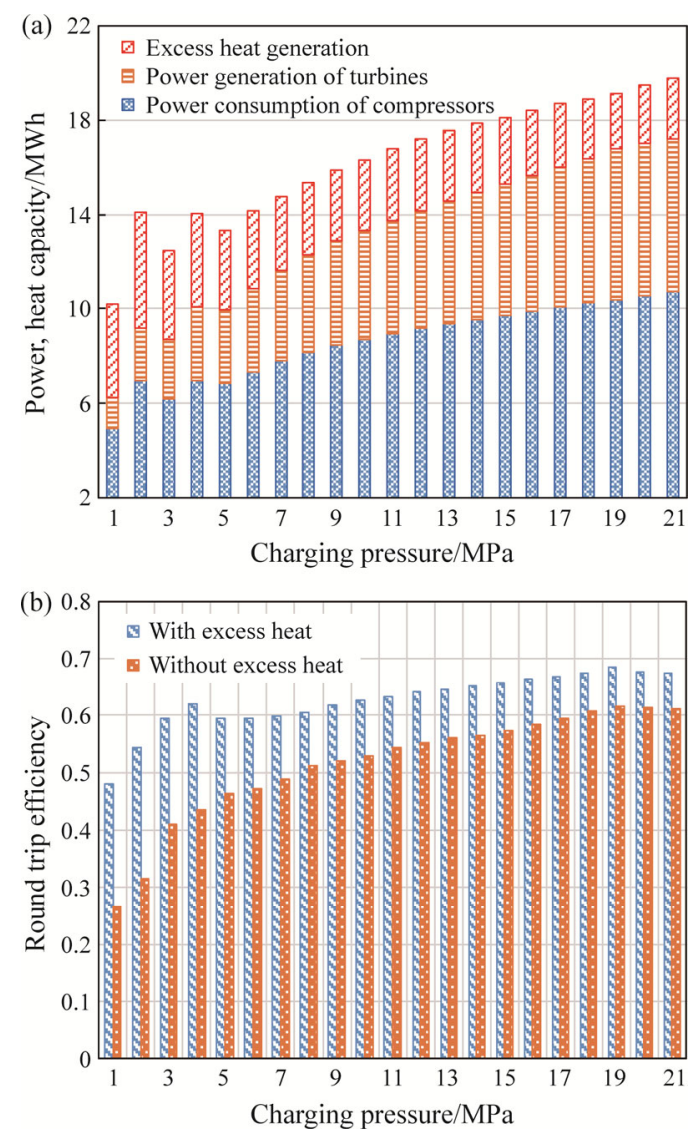

Fig. 9 Effect of charging pressure on the performance of the baseline LAES

Fig. 9(b) suggests that the eRTE with excess heat (i.e., the maximum electrical round trip efficiency) lies between $48 \%$ and $69 \%$ and is much higher than that without excess heat. Importantly and somewhat unexpected, the baseline LAES with excess heat also has a high eRTE at lower charging pressures; a local maximum of $62 \%$ is achieved at a charging pressure of $\sim 4 \mathrm{MPa}$. As a result, the performance of the baseline LAES, especially at low charging pressures has been somewhat underestimated in the past. The main reason for this is that the past research has only considered eRTE with the excess heat ignored, which can be highly valuable for small scale applications such as the 
integration of the baseline LAES with decentralized local micro-energy networks where there are demands on heating, cooling and hot water on top of power.

The discussion above suggests the potential of a multi-functional LAES, namely the hybrid LAES as described earlier in this paper. The analyses in the following sub-sections will be on the hybrid LAES, where a direct comparison will be made on the supply capacities (cooling, heating, hot water and power) in the discharging process with the same power consumption in the charging process (namely, the air flow rate varies with the charging pressure). As the multi-functional hybrid LAES is mainly applicable to decentralized local micro-grids, we shall consider the net power consumption in the charging process as $1 \mathrm{MW}$ and the charging lasts for 8 hours (the total power consumption of 8 MWh).

\subsection{The hybrid LAES for power, hot water and cooling supply in summer (PHC mode)}

A Sankey diagram of exergy flow in the hybrid LAES system is shown in Fig. 10 for providing power, hot water and cooling in summer, where both the discharging and charging pressure are at $12 \mathrm{MPa}$. The charging cycle and discharging cycle have a high exergy efficiency of $87 \%$ and $84 \%$, respectively, while the conversion of excess heat to cooling and hot water has a low exergy efficiency of $20 \%$.

Fig. 11 shows the supply capacity of the hybrid LAES for power, hot water and cooling (PHC) during discharging, for a given power consumption of $8 \mathrm{MWh}$ $(1 \mathrm{MW} \times 8 \mathrm{~h})$ in the charging process. The cooling supply capacity has an overall decreasing trend, changing from
1.36 to $0.28 \mathrm{MWh}$, as the charging pressure increases from 1 to $21 \mathrm{MPa}$. Fluctuations in the cooling supply capacity are observed between 1 and $7 \mathrm{MPa}$ due to changes in the excess heat generation as a result of changes in the compressor type and/or compression stage as explained earlier in the paper. The hot water supply capacity decreases gradually from 5.72 to $1.4 \mathrm{MWh}$ as the charging pressure increases from 1 to $21 \mathrm{MWh}$. The hybrid LAES is seen to give the largest power supply capacity of $4.94 \mathrm{MWh}$ at a charging pressure of $19 \mathrm{MPa}$. However, at this charging pressure, the cooling and hot water supply capacities are at a low level. At a charging pressure of $1 \mathrm{MPa}$, the hybrid LAES has the lowest power supply capacity of $2.14 \mathrm{MWh}$, while the cooling and hot water supply capacities are at the largest, being respectively 1.36 and $5.72 \mathrm{MWh}$.

\subsection{The hybrid LAES for power, hot water and heating supply in winter (PHH mode)}

Fig. 12 shows the supply capacity of the hybrid LAES for power, hot water and heating (PHH) during discharging for a given amount of power consumption of $8 \mathrm{MWh}(1 \mathrm{MW} \times 8 \mathrm{~h})$ during charging. One can see that the heating supply capacity decreases gradually from 4.72 to $1.22 \mathrm{MWh}$ as the charging pressure increases from 1 to $21 \mathrm{MPa}$. This gives the minimum heating supply capacity of $1.22 \mathrm{MWh}$ at the charging pressure of $21 \mathrm{MPa}$. The hot water supply capacity varies between 0.27 and $1.36 \mathrm{MWh}$ with the charging pressure increased from 1 to $21 \mathrm{MPa}$, and the maximum and minimum hot water capacities occur respectively at a charging pressure of 1 and $21 \mathrm{MPa}$. At the charging pressure of $1 \mathrm{MPa}$, the hybrid LAES has the lowest power supply capacity, but

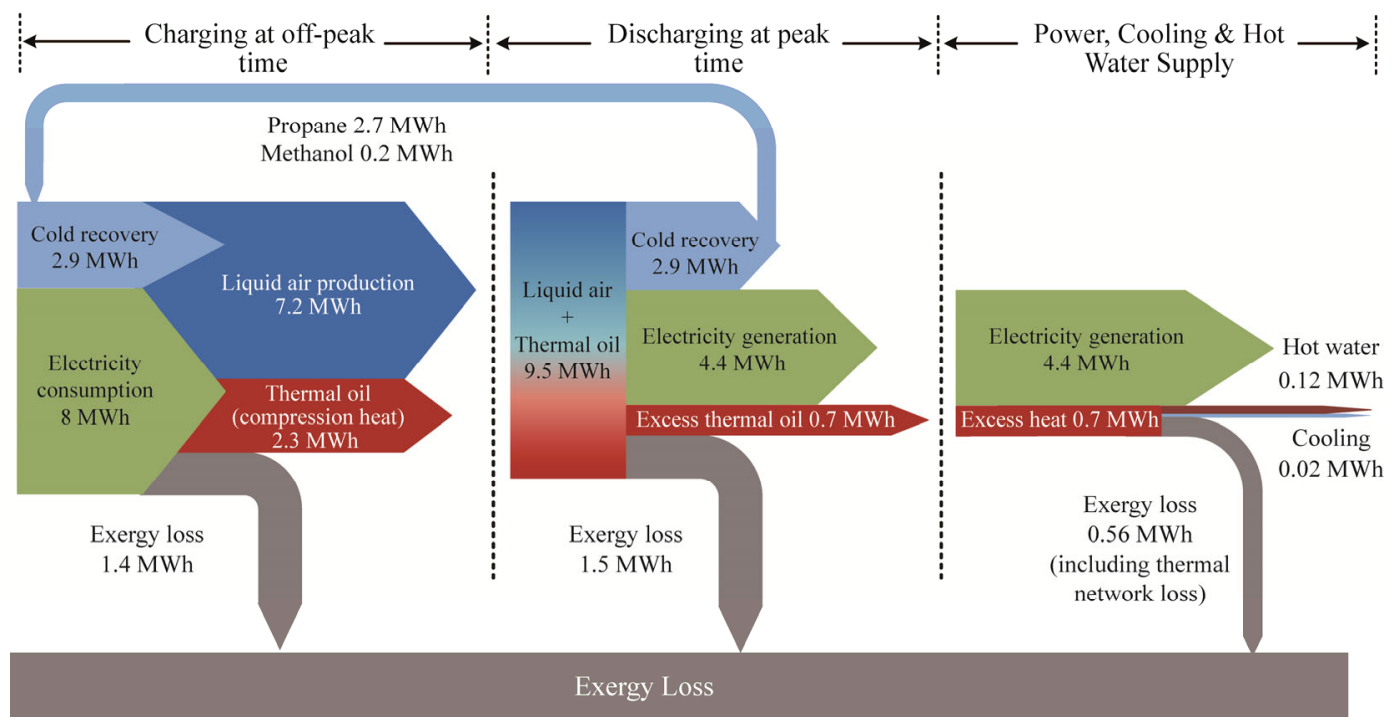

Fig. 10 Sankey diagram of exergy flow in the hybrid LAES system for providing power, hot water and cooling in summer (charging/discharging pressure at $12 \mathrm{MPa}$ ) 


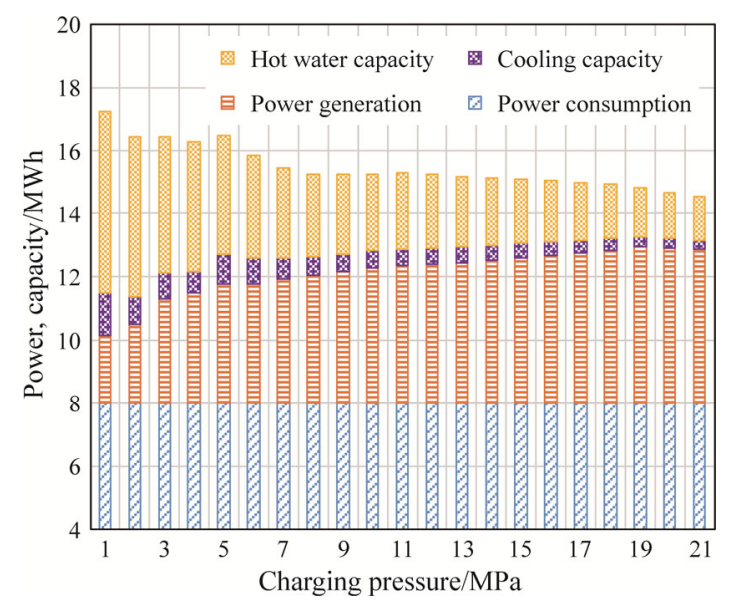

Fig. 11 Supply capacity of the hybrid LAES system for power, hot water and cooling in summer

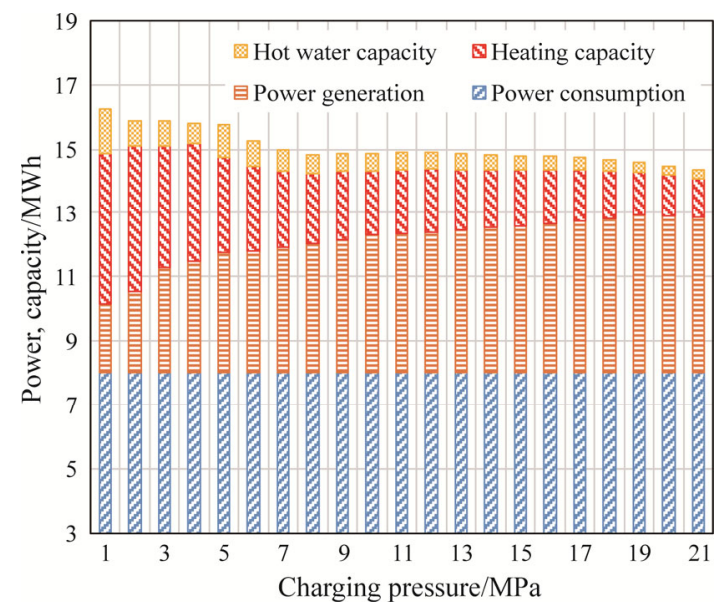

Fig. 12 Supply capacity of the hybrid LAES system for power, hot water and heating in winter

provides the largest heating and hot water supply capacities. At the charging pressure of $19 \mathrm{MPa}$, the hybrid LAES has the largest power supply capacity, but gives much lower heating and hot water supply capacities.

\subsection{The hybrid LAES for power and hot water supply in spring or autumn (PH mode)}

Fig. 13 shows the supply capacities of the hybrid LAES for power and hot water $(\mathrm{PH})$ during discharging, for a given amount of power consumption of $8 \mathrm{MWh}(1$ $\mathrm{MW} \times 8 \mathrm{~h}$ ) in the charging process. The hot water supply capacity decreases considerably from 6.09 to $2.79 \mathrm{MWh}$ as the charging pressure increases from 1 to $8 \mathrm{MPa}$, which is followed by a slow decrease from 2.79 to 1.49 MWh with a further increase in the charging pressure from 8 to $21 \mathrm{MPa}$. The hybrid LAES has the highest hot water supply capacity of $6.09 \mathrm{MWh}$ at the charging pressure of $1 \mathrm{MPa}$ at which the power supply capacity is at the lowest of $2.14 \mathrm{MWh}$. As the charging pressure is at $19 \mathrm{MPa}$, the hybrid LAES gives the maximum power supply capacity of $4.94 \mathrm{MWh}$ but a much lower hot water supply capacity of $1.66 \mathrm{MWh}$.

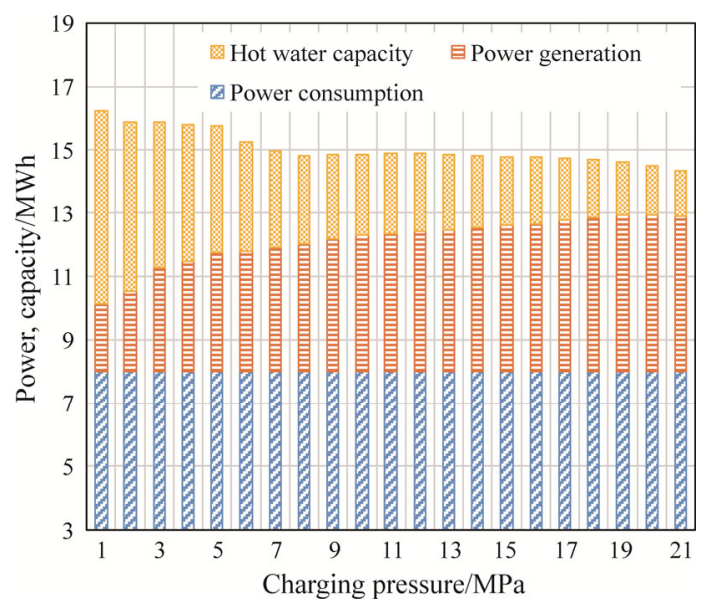

Fig. 13 Supply capacity of the hybrid LAES system for power and hot water in spring or autumn

\subsection{Nominal-electrical round trip efficiency of the hybrid LAES system}

The nominal-electrical round trip efficiency (neRTE) of the hybrid LAES system is shown in Fig. 14 with the three working modes of $\mathrm{PHC}$ in summer, $\mathrm{PHH}$ in winter, and $\mathrm{PH}$ in spring or autumn in the UK. The value of the neRTE is affected by the power consumption of air compressors, liquid air yield and the amount of excess heat. An increase of the charging pressure would increase the power consumption of air compressors, but the effect on the liquid air yield and the amount of excess heat is different (see Fig. 8).

The neRTE increases significantly as the charging pressure increases from 1 to $5 \mathrm{MPa}$, as shown in Fig. 14(a), which is mainly due to the dramatic increase of the liquid air yield. A further increase of the charging pressure to $7 \mathrm{MPa}$ leads to a gradual decrease of the neRTE, resulting from the decrease of the amount of excess heat and the increase of power consumption of air compressors. With the charging pressure increasing from 7 to $17 \mathrm{MPa}$, the neRTE increases gradually because of the gradual increase of the liquid air yield. A further increase of the charging pressure results in the decrease of the neRTE which is mainly affected by the increase of power consumption of air compressors. Overall, the hybrid LAES has a high neRTE, ranging between 52\% and $76 \%$ under the studied conditions. The highest neRTE of $76 \%$ is achieved as the charging pressure is $\sim 5$ $\mathrm{MPa}$ for summer conditions. A high neRTE is also observed with the charging pressure at $5 \mathrm{MPa}$ for winter, spring and autumn conditions. 
Fig. 14(b) compares the neRTE of the hybrid LAES system for winter conditions with gas boilers (the current case) and air-source heat pumps (the future case). For the current case using gas boilers for heating and hot water, the hybrid LAES system has a high neRTE above $70 \%$. As air-source heat pumps are used for heating and hot water in the future, the hybrid LAES system has a lower neRTE, indicating air-source heat pumps are more energy efficient than gas boilers. Finally, the hybrid LAES system is suggested to work at the charging pressure of 5 $\mathrm{MPa}$, which has the local maximum neRTE and contributes to a lower capital cost.

\section{(a)}

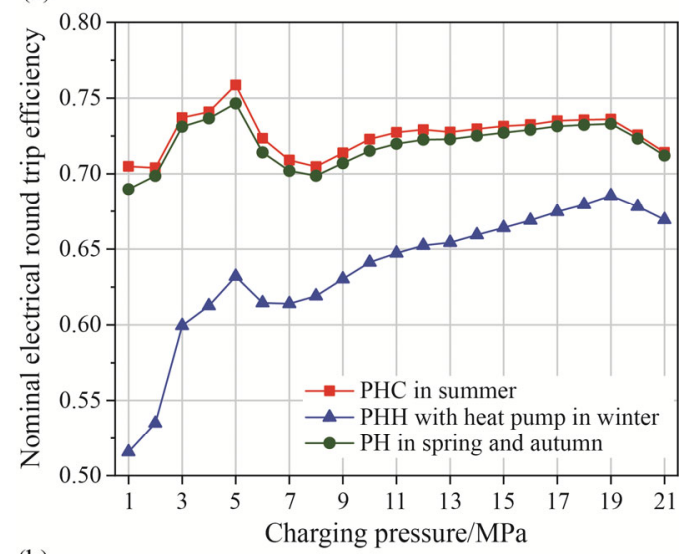

(b)

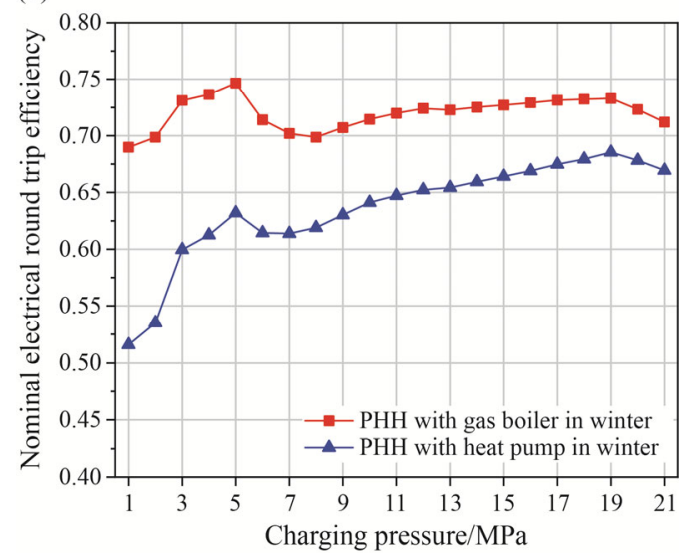

Fig. 14 The nominal-electrical round trip efficiency of the hybrid LAES system

\subsection{Primary energy savings and avoided carbon dioxide emissions}

Fig. 15 shows the potential of the hybrid LAES system to reduce primary energy consumptions and carbon dioxide emissions with the charging pressure at 5 $\mathrm{MPa}$, where power consumption is $8 \mathrm{MWh}(1 \mathrm{MW} \times 8 \mathrm{~h})$ in the charging process. The primary energy savings of the hybrid LAES system vary between 10.1 and 12.1 MWh, with the maximum achieved in the summer conditions (PHC mode). The avoided carbon dioxide emissions fluctuate between 1.9 and 2.3 ton, indicating that the hybrid LAES system is promising to reduce carbon emissions and contribute to a low carbon future.

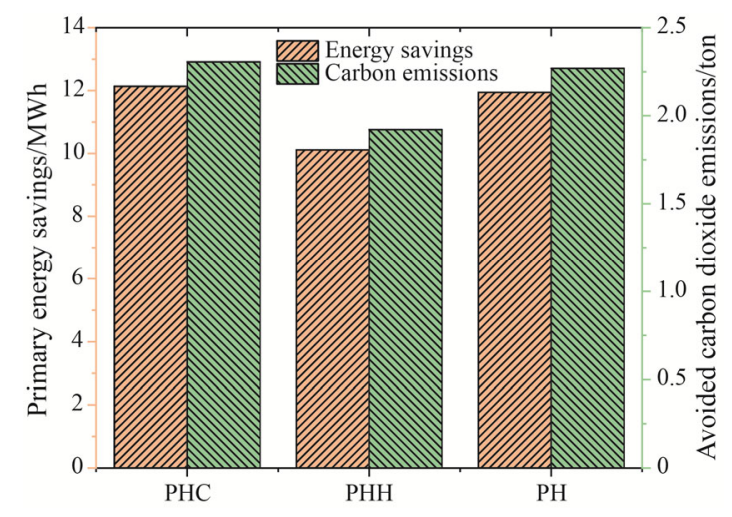

Fig. 15 Primary energy savings and avoided carbon emissions by the hybrid LAES system (charging pressure at 5 $\mathrm{MPa})$

\section{Conclusions}

Large-scale standalone LAES systems often use a charging pressure at $\sim 10 \mathrm{MPa}$ and have an electrical round trip efficiency (eRTE) below 60\%. We first investigate the performance of a standalone LAES (termed as a baseline LAES) over a far wider range of charging pressure ( 1 to $21 \mathrm{MPa}$ ), and find that the baseline LAES could achieve a maximum eRTE above $60 \%$ at a charging pressure of $19 \mathrm{MPa}$. The baseline LAES, however, produces a large amount of excess heat particularly at low charging pressures with the maximum occurred at $\sim 1 \mathrm{MPa}$. Such excess heat can be valuable if the baseline LAES is used for a decentralized microenergy network for residential communities and/or industrial/commercial centres. In such cases, the performance of the baseline LAES, especially at low charging pressures, is underestimated by only considering electrical energy in the past.

By considering the excess heat, the eRTE of the baseline LAES is evaluated, which shows a high value even at lower charging pressures; the local maximum of $62 \%$ is obtained at $\sim 4 \mathrm{MPa}$ and the overall maximum of $69 \%$ is observed at $19 \mathrm{MPa}$. Therefore, the baseline LAES has the potential to achieve a high efficiency at low charging pressures by effective use of the excess heat.

A hybrid LAES system is then proposed by using the excess heat to provide cooling, heating and hot water for decentralized micro-energy networks. To evaluate the efficiency of the hybrid LAES system, the energy for supplying cooling, heating and hot water is turned into equivalent electrical energy and a nominal-electrical round trip efficiency (neRTE) is proposed for the 
evaluation of the hybrid LAES performance. What's more, the primary energy savings and avoided carbon dioxide emissions are also evaluated for the hybrid LAES system. Three operation modes of the hybrid system are studied to meet the end-user demands in London, UK: Cooling, Hot water and Power supply in summer; Heating, Hot water and Power supply in winter; Hot water and Power supply in spring and autumn.

Results show that the hybrid LAES can achieve a high neRTE between $52 \%$ and $76 \%$, with the maximum achieved at a lower charging pressure of $\sim 5 \mathrm{MPa}$. The primary energy savings and avoided carbon dioxide emissions are up to $12.1 \mathrm{MWh}$ and 2.3 ton, respectively, with a given power consumption of $8 \mathrm{MWh}(1 \mathrm{MW} \times 8 \mathrm{~h})$ in the charging process, indicating that the hybrid LAES system is promising to contribute to a low carbon future. These new findings suggest, for the first time, that small-scale LAES systems can be best operated at low charging pressures and that the technologies have a great potential for applications in local decentralized micro energy grids.

\section{Acknowledgements}

The authors are grateful for the partial support from UK EPSRC Manifest Project under EP/N032888/1, EP/P003605/1, a UK FCO Science \& Innovation Network grant (Global Partnerships Fund) and an IGI/ IAS Global Challenges Funding (IGI/IAS ID 3041).

\section{References}

[1] Renewables 2019 Global Status Reports, www.ren21.net.

[2] Li Y., Chen H., Ding Y., Fundamentals and applications of cryogen as a thermal energy carrier: A critical assessment. International Journal of Thermal Sciences, 2010, 49(6): 941-949.

[3] Morgan R., Nelmes S., Gibson E., Brett G., Liquid air energy storage-analysis and first results from a pilot scale demonstration plant. Applied Energy, 2015, 137: 845853.

[4] Guizzi G.L., Manno M., Tolomei L.M., Vitali R.M., Thermodynamic analysis of a liquid air energy storage system. Energy, 2015, 93: 1639-1647.

[5] Sciacovelli A., Vecchi A., Ding Y.L., Liquid air energy storage (LAES) with packed bed cold thermal storage-From component to system level performance through dynamic modelling. Applied Energy, 2017, 190: 84-98.

[6] Peng H., Yang Y., Li R., Ling X., Thermodynamic analysis of an improved adiabatic compressed air energy storage system. Applied Energy, 2016, 183: 1361-1373.

[7] Peng H., Shan X., Yang Y., Ling X., A study on performance of a liquid air energy storage system with packed bed units. Applied Energy, 2018, 211: 126-135.

[8] She X., Li Y., Peng X., et al., Theoretical analysis on performance enhancement of stand-alone liquid air energy storage from perspective of energy storage and heat transfer. Energy Procedia, 2017, 142: 3498-3504.

[9] Lin B., Wu W., Bai M., Xie C., Radcliffe J., Liquid air energy storage: Price arbitrage operations and sizing optimization in the GB real-time electricity market. Energy Economics, 2019, 78: 647-655.

[10] Li Y., Wang X., Ding Y.L., An optimal design methodology for large-scale gas liquefaction. Applied Energy, 2012, 99(6): 484-490.

[11] Ameel B., T'Joen C., Kerpel K.D., et al., Thermodynamic analysis of energy storage with a liquid air Rankine cycle. Applied Thermal Engineering, 2013, 52(1): 130-140.

[12] Morgan R., Nelmes S., Gibson E., Brett G., An analysis of a large-scale liquid air energy storage system. Energy, 2015, 168(2): 1-10.

[13] Borri E., Tafone A., Romagnoli A., et al., A preliminary study on the optimal configuration and operating range of a "microgrid scale" air liquefaction plant for Liquid Air Energy Storage. Energy Conversion \& Management, 2017, 143: 275-285.

[14] Hamdy S., Morosuk T., Tsatsaronis G., Cryogenics-based energy storage: Evaluation of cold exergy recovery cycles. Energy, 2017, 138: 1069-1080.

[15] She X., Peng X., Nie B., Leng G., Zhang X., Weng L., et al., Enhancement of round trip efficiency of liquid air energy storage through effective utilization of heat of compression. Applied Energy, 2017, 206: 1632-1642.

[16] Peng X., She X., Cong L., et al., Thermodynamic study on the effect of cold and heat recovery on performance of liquid air energy storage. Applied Energy, 2018, 221: 86-99.

[17] Li Y., Cao H., Wang S., et al., Load shifting of nuclear power plants using cryogenic energy storage technology. Applied Energy, 2014, 113(1): 1710-1716.

[18] Wu S., Zhou C., Doroodchi E., Moghtaderi B., Technoeconomic analysis of an integrated liquid air and thermochemical energy storage system. Energy Conversion and Management, 2020, 205: 112341.

[19] Lee I., Park J., Moon I., Conceptual design and exergy analysis of combined cryogenic energy storage and LNG regasification processes: cold and power integration. Energy, 2017, 140: 106-115.

[20] Antonelli M., Barsali S., Desideri U., et al., Liquid air energy storage: Potential and challenges of hybrid power plants. Applied Energy, 2017, 194: 522-529.

[21] Kim J., Noh Y., Chang D., Storage system for distributedenergy generation using liquid air combined with liquefied natural gas. Applied Energy, 2018, 212: 1417-1432.

[22] She X., Zhang T., Cong L., et al., Flexible integration of 
SHE Xiaohui et al. LAES for decentralized micro energy networks with combined cooling, heating, hot water and power supply 17

liquid air energy storage with liquefied natural gas regasification for power generation enhancement. Applied Energy, 2019, 251: 113355.

[23] Ahmad A., Al-Dadah R., Mahmoud S., Liquid nitrogen energy storage for air conditioning and power generation in domestic applications. Energy Conversion \& Management, 2016, 128: 34-43.

[24] Ahmad A., Al-Dadah R., Mahmoud S., Liquid air utilization in air conditioning and power generating in a commercial building. Journal of Cleaner Production, 2017, 149: 773-783.

[25] Al-Zareer M., Dincer I., Rosen M.A., Analysis and assessment of novel liquid air energy storage system with district heating and cooling capabilities. Energy, 2017, 141: 792-802.

[26] Wang C., Akkurt N., Zhang X., Luo Y., She X., Technoeconomic analyses of multi-functional liquid air energy storage for power generation, oxygen production and heating. Applied Energy, 2020, 275: 115392.

[27] Wang Z., Zhou N., Guo J., Wang X., Fluid selection and parametric optimization of organic Rankine cycle using low temperature waste heat. Energy, 2012, 40: 107-115.

[28] https: //www.ciphe.org.uk/consumer/safe-water-campaign/ hot-water-scalds/.

[29] https: //www.atlascopco.com/en-uk/compressors.

[30] PIP REEC001 Compressor Selection Guidelines, 2013,
Process Industry Practices Machinery.

[31] Zheng J., Zhou Z., Zhao J., Wang J., Integrated heat and power dispatch truly utilizing thermal inertia of district heating network for wind power integration. Applied Energy, 2018, 211: 865-874.

[32] https://www.britishgas.co.uk/home-services/boilers-andheating/guides/boiler-efficiency.html.

[33] Joachim K., Halliwell I., Propulsion and power: An exploration of gas turbine performance modeling. Springer, 2018.

[34] Hundy G.F., Trott A.R., Welch T.C., Refrigeration, air conditioning and heat pumps. Fifth Edition, 2016, Elsevier Ltd. ISBN 978-0-08-100647-4.

[35] Atienza-Marquez A., Bruno J.C., Akisawa A., Nakayama M., Coronas A., Fluids selection and performance analysis of a polygeneration plant with exergy recovery from LNG-regasification. Energy, 2019, 176: 1020-1036.

[36] Pátek J., Klomfar J., A computationally effective formulation of the thermodynamic properties of $\mathrm{LiBr}-\mathrm{H}_{2} \mathrm{O}$ solutions from 273 to $500 \mathrm{~K}$ over full composition range. International Journal of Refrigeration, 2006, 29: 566-578.

[37] Talbi M.M., Agnew B., Exergy analysis: an absorption refrigerator using lithium bromide and water as the working fluids. Applied Thermal Engineering, 2000, 20 : 619-630. 